\title{
EDUCAÇÃO AMBIENTAL NO ENSINO FUNDAMENTAL: ENSINAR A CONHECER "MICROALGAS" PARA PRESERVAÇÃO DOS CORPOS D'ÁGUA
}

\author{
Juliana Ferreira da Silva ${ }^{1}$
}

\section{RESUMO}

Como estratégia para a preservação dosambientes aquáticos, foi aplicada uma oficina com atividade prática a alunos do 6ㅇ ao 9o ano da Escola Estadual de Ensino Fundamental Arroio Grande, $4^{\circ}$ Distrito de Santa Maria, Rio Grande do Sul. A forma avaliativa foi por meio de questionários respondidos dias antes da oficina e um mês após esta. Inicialmente uma palestra teve como proposta apresentar e provocar a reflexãoda existência e a importância das microalgas nos ambientes aquáticos. Posteriormente, os alunos observaram, em microscópios ópticos, microalgas de corpos d'água próximos da escola, espécies de culturas e em lâminas permanentes. Avaliando os questionários, pode-se perceber que as atividades desenvolvidas facilitaram a compreensão e a assimilação de conceitos sobre a temática abordada, sensibilizando os alunos para a importância da preservação dos corpos d'água.

Palavras-chave:Conservação. Educação Ambiental. Ensino Fundamental.

ENVIRONMENTAL EDUCATION IN FUNDAMENTAL TEACHING: TEACHING TO KNOW "MICROALGAS" FOR PRESERVATION OF WATER BODIES

\begin{abstract}
The strategy for the preservation of aquatic environments, a workshop with practical activity was applied to students from the 6th to 9th grade of the State School of Elementary EducationArroio Grande, $4^{\circ}$ Santa Maria District of Rio Grande do Sul. The evaluative form was through questionnaires answered days before the workshop and one month after this. Initially a lecture had as proposal to present and provoke the reflection of the existence and importance of microalgae in aquatic environments. Subsequently, the students observed, in optical microscopes, microalgae of bodies of water near the school, species of cultures and in permanent slides. Evaluating the questionnaires, one can see that the activities developed facilitated the understanding and the assimilation of concepts on the subject addressed, sensitizing the students to the importance of the preservation of water bodies.
\end{abstract}

Keywords:Conservation. Environmental education. Elementary School.

\footnotetext{
${ }^{1}$ Universidade Federal de Santa Maria.
} 


\section{INTRODUÇÃO}

Os ambientes aquáticos são de grande importância à vida dos seres vivos e, o Brasil, possui situação privilegiada em relação à riqueza desses ambientes. No entanto, nos últimos anos, os ambientes aquáticos vêm sendo negligenciados quanto a sua conservação, especialmente, quanto aos seres vivos que neles habitam. Diante dessa problemática vivida, a Educação Ambiental é fundamental para a proteção e manutenção deste bem essencial à vida.

A educação ambiental é um processo permanente no qual os indivíduos e a comunidade tomam consciência, valores e a determinação que os tornam capazes de agir, individualmente ou coletivamente, na busca de soluções para os problemas ambientais (UNESCO, 1997). A escola dentro da Educação Ambiental deve sensibilizar o aluno a buscar valores que conduzam a uma convivência harmoniosa com o ambiente e as demais espécies que habitam o planeta, auxiliando-o a analisar criticamente os princípios que tem levado à destruição inconsequente dos recursos naturais e de várias espécies (EFFTING, 2007). Segundo Edna Sueli Pontalti (2005), Educadora Ambiental, "a escola é o espaço social e o local onde o aluno dará sequência ao seu processo de socialização, iniciado em casa, com seus familiares". Assim, é evidente a importância da escola no processo de formação, tanto social quanto ambiental, dos seus alunos. Mas, infelizmente, durante o período letivo os professores não conseguem abordar com grande ênfase e agregar uma atividade prática diferente como uma aula em campo, devido à alta carga horária de trabalho e também devido à falta de conhecimento de assuntos específicos (como as microalgas), se detendo, no período letivo, a ministrar somente as aulas teóricas dos conteúdos curriculares pré-estabelecidos.

As temáticas ensinadas exigem aulas práticas e vivenciadas, havendo assim a formação de uma atitude científica, que está intimamente vinculada ao modo como se constrói o conhecimento (FUMAGALLI, 1993). As atividades práticas podem ser utilizadas como importante estratégia em programas de Educação Ambiental, umavez que o contato com 0 ambiente permite a sensibilização acerca dos problemas ambientais. Além disso, surgem 
oportunidades de reflexão sobre valores, imprescindíveis as mudanças comportamentais e, sobretudo, atitudinais (CARVALHO, 1998).Além de ajudar no desenvolvimento de conhecimentos científicos, as aulas práticas permitem que os estudantes aprendam como abordar objetivamente o seu mundo e como desenvolver soluções para problemas complexos (LUNETTA, 1991). Servem também como estratégia e podem auxiliar o professor a construir com os alunos uma nova visão sobre um mesmo tema (LEITE et al., 1998).

Diante da problemática ambiental vivida atualmente nos ambientes aquáticos é de fundamental importância a conscientização a partir de uma Educação Ambiental fundamentada, ou seja, a partir das vivencias, do que se conhece, dando lógica ao processo de conscientização. No caso dos sistemas aquáticos o primeiro passo é conhecer os organismos que ali estão presentes assim como levar a uma compreensão da importância destes, entre os organismos existentes temos as microalgas.

As microalgas fazem parte de grupo muito heterogêneo de microrganismos algais com clorofila e outros pigmentos fotossintéticos capazes de realizar a fotossíntese oxigênica (PÉREZ, 2007). No entanto, como são seres, geralmente, microscópicos, a sua importância não é visível e precisa ser ensinada e valorizada, o que pode ser atingido por meio da educação ambiental, em especial, dentro da escola.

O presente trabalho teve como objetivo contribuir com conceitos e práticas sobre o tema "microalgas", tendo em vista à sensibilização ambiental dos alunos relacionada à preservação de corpos d'água. Sensibilizar sobre a importância do "micromundo" dos ambientes aquáticos para a melhor qualidade dos ambientes, conhecer as microalgas existentes nos corpos d'agua próximos e a partir do conhecimento, levar a uma reflexão da importância das microalgas nos ambientes aquáticos foram os objetivos do presente trabalho.

\section{MATERIAL E MÉTODOS}

O estudo foi realizado na Escola Estadual de Ensino Fundamental Arroio Grande, no período de maio a julho de 2015. A escola está situada do 4 은 distrito de Santa Maria, Arroio Grande (Figura 1). 


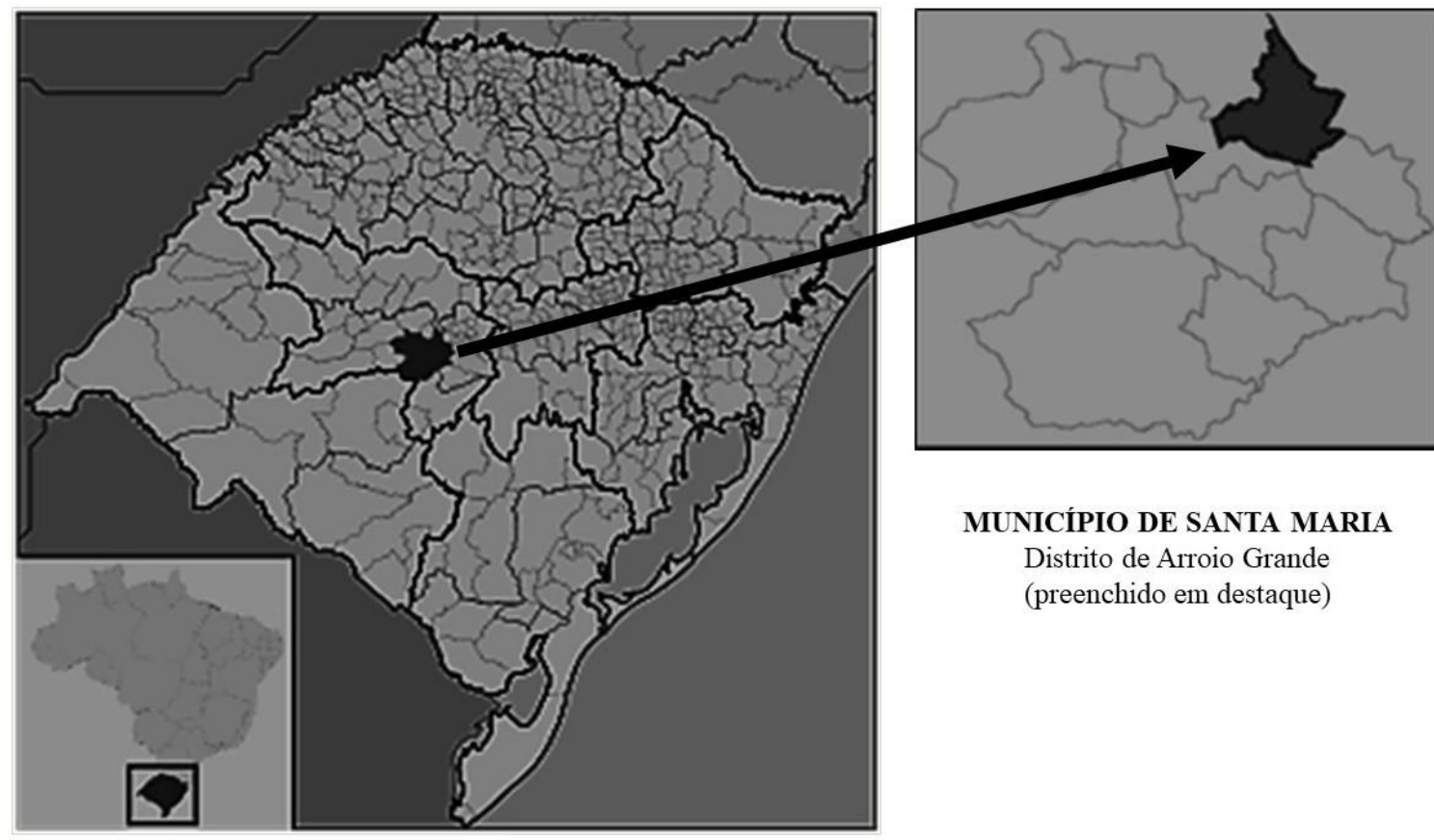

Figura 1. Mapa do estado do Rio Grande do Sul (Brasil). Em detalhe, o município de Santa Maria destacando, preenchido em destaque, o $4^{\circ}$ distrito de ArroioGrande. Fonte: https://pt.wikipedia.org/wiki/Arroio Grande (distrito de Santa Maria) (adaptado).

O presente trabalho contou com uma pesquisa exploratória de modo que buscou inicialmente constatar o conhecimento prévio dos alunos envolvidos. $O$ estudo contou com a participação de 50 alunos no pré-questionário distribuídos entre o $6^{\circ}, 7^{\circ}, 8^{\circ}$ e $9^{\circ}$ ano da escola. O questionário foi aplicado pela professora regente duas semanas antes da palestra e oficina para que os alunos respondessem de forma mais fiel possível. A repetição ocorreu da mesma forma duas semanas após a aplicação das atividades, onde 43 alunos responderam ao questionário.

Por meio de 10 questões os alunos foram questionados quanto a conceitos e a percepção dos ambientes aquáticos ao seu entorno. A maioria das questões objetivas, sendo a forma mais eficiente quando se tem o intuito de avaliar o grau de compreensão de conceitos. Dessa forma, também tornou o questionário rápido de ser respondido e compreendido. A última questão possibilitou os alunos expressarem na forma de desenhos a observação do meio aquático ao seu entorno, refletindo o que observam (de fato) e o que conhecem sobre o ambiente aquático. A partir disso, por meio de uma análise quali-quantitativa que foi aplicada nos questionários buscou a resposta dos 
questionamentos iniciais. De forma também descritiva obteve-se a análise dos resultados.

A palestra teve como objetivo mostrar o papel das microalgas nos ambientes aquáticos, alertar sobre a sua importância, além de mostrar os principais grupos que podem ser visualizadosnos corpos d'água apresentando suas principais características. A partir do conhecimento dos conteúdos ministrados em sala de aula com o professor, procurou-se situar esses conteúdos trabalhados antes nas aulas letivas também na palestra. Conteúdos como: cadeia alimentar, ecologia, reinos e fotossíntese foram trabalhados novamente na palestra. Os alunos foram divididos em três grupos para que houvesse um quantitativo semelhante em cada palestra que era precedida da oficina prática.

Para oficina prática, os alunos e alunas divididos em quatro grupos fizeram uso de microscópios do Projeto "O mundo microscópico" do Ministério da Educação havia também um microscópio óptico (Figura 2). Na oficina os alunos observaram lâminas permanentes com diatomáceas epilíticas pertencentes a Bacia Hidrográfica do Arroio Grande localizada na região onde se insere a escola. Também puderam preparar lâminas provisórias com amostras de rio e açudes situados próximos a escola. Amostras cultivadas de três espécies de cianobactérias (Dolichospermumsp., Microcystissp., Synechococcussp.) e três espécies de clorofíceas (Ankistrodesmussp., Desmodesmussp., kirchneriellasp.) foram também observadas por meio de lâminas provisórias confeccionadas pelos próprios alunos. 


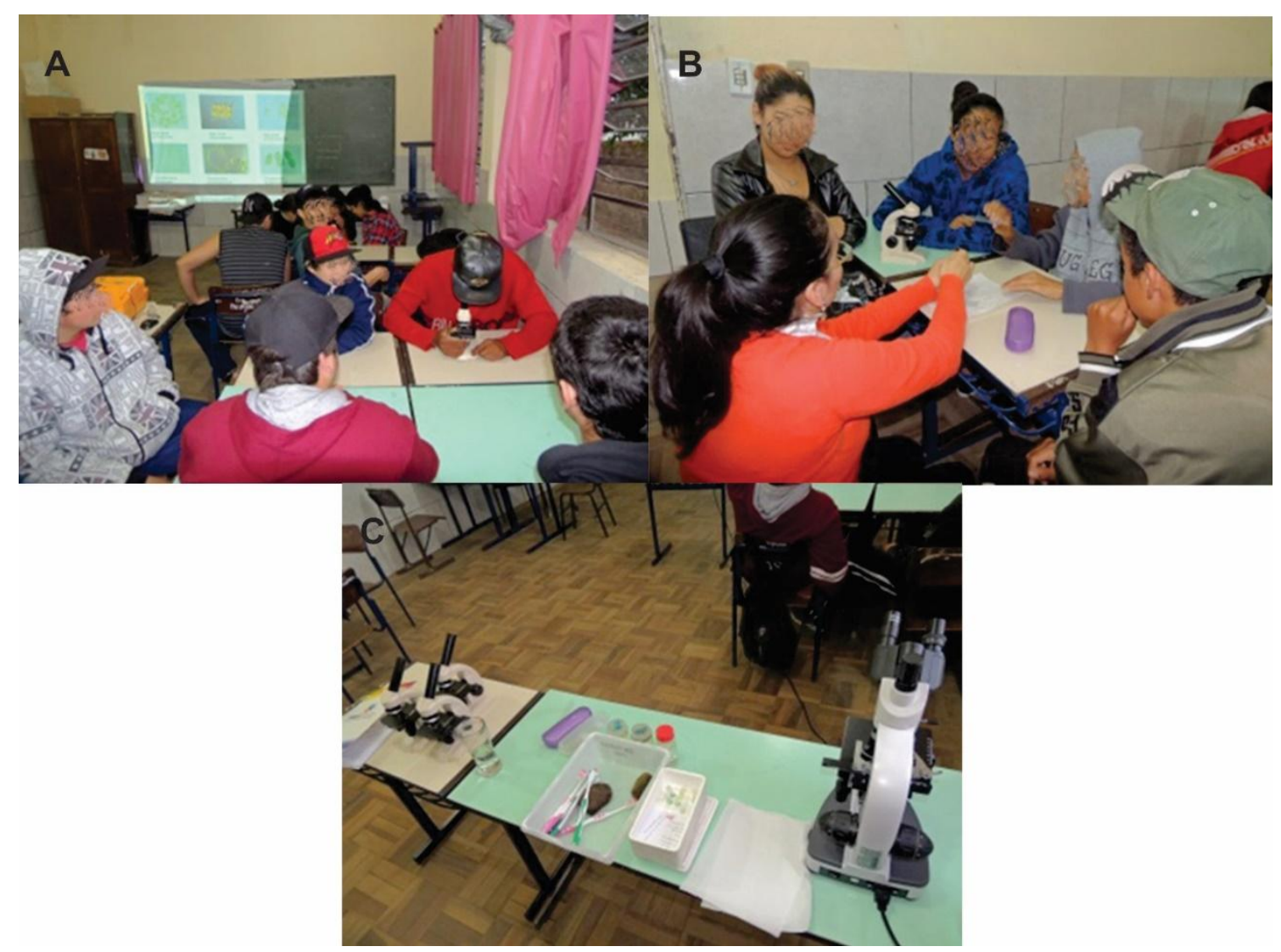

Figura 2. Oficina realizada na Escola Estadual de Ensino Fundamental Arroio Grande (RS, Brasil). A: Processo de preparação das amostras para observação; B: Discussões e observações do material e C: Material utilizado na atividade prática. Fonte: Autor

\section{RESULTADOS E DISCUSSÃO}

Cinquenta alunos responderam o questionário inicial, já o questionário após as atividades, contou com 43 respondentes.Ao utilizarem os microscópios para visualizarem as microalgas presente nos corpos d'água (rio e açude) próximo à escola, tanto nas lâminas permanentes e nas algumas espécies cultivadas, pode-se observar a mobilização, o empenho e a curiosidade de todos os alunos. Segundo Evangelista e Soares (2011) as atividades práticas proporcionam momentos de descontração, incertezas e aguçam o sentimento de exploração além de desenvolver maior aproximação com a vida real, além de possibilitar a avaliação dos discentes através da sua participação da atividade.

Segundo Marques (1993), um trabalho de educação ambiental será mais rico se tiver como base um levantamento das formas de percepção do ambiente.Acreditamos que essa percepção parte de conhecimentos básicos, 
entre eles os conceitos. No questionário inicial foi possível observar que $78 \%$ dos alunos desconhecia o que é um corpo d'água (Figura 7). Após a aplicação da palestra e oficina, esse conceito já se tornou conhecido por $60,46 \%$ dos respondentes.

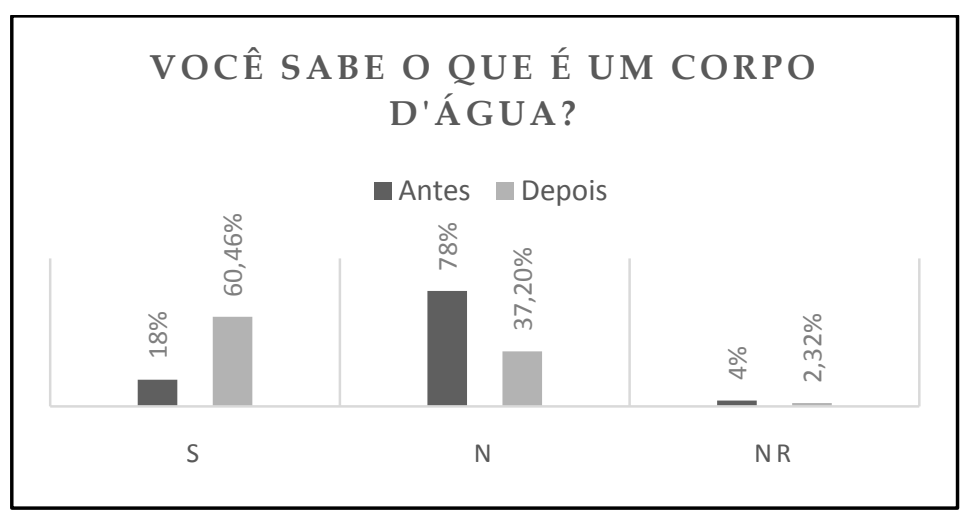

Figura 3. Respostas a "Questão 1" dos alunos da Escola Estadual de Ensino FundamentalArroio Grande RS, Brasil (S: Sim; N: Não; NR: Não responderam).

Quando questionados a respeito se sabiam o que era um ambiente aquático pode-se observara que este conceito já era bem conhecido por todos e que se fortaleceu após as atividades (Figura 4).

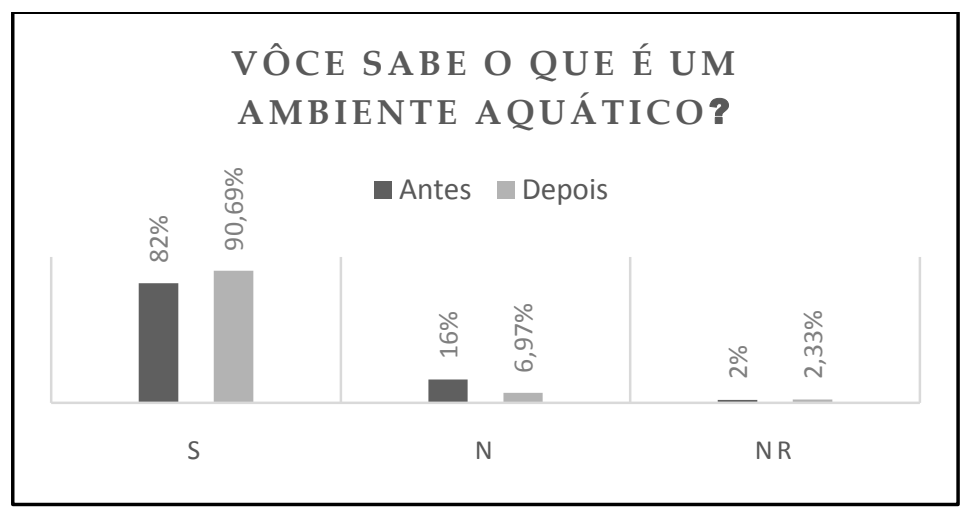

Figura 4. Respostas a "Questão 2" dos alunos da Escola Estadual de Ensino FundamentalArroio Grande RS, Brasil (S: Sim; N: Não; NR: Não responderam).

No questionário inicial foi possível observar que 54\% dos alunos conheciam uma alga (Figura 5). Após as atividades, esse conceito já se tornou ainda mais claro, onde $69,76 \%$ dos respondentes responderam sobre 0 conhecimento. 


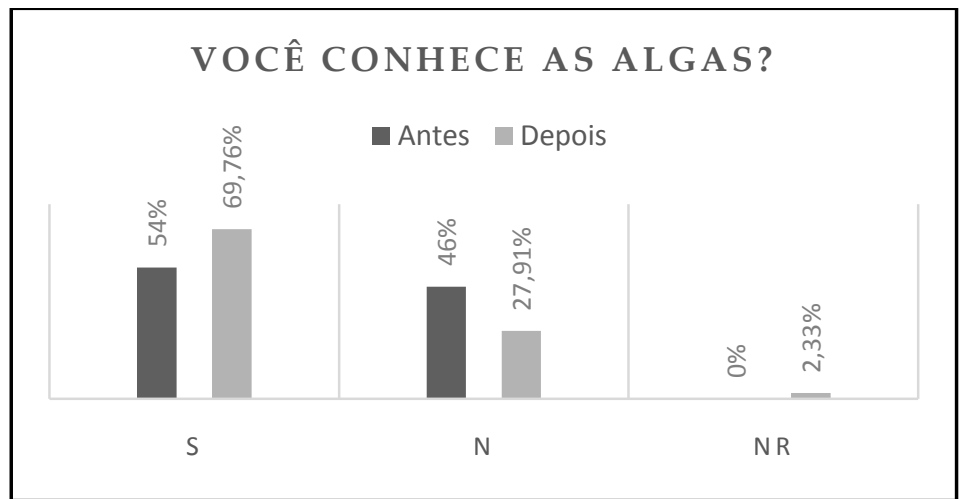

Figura 5. Respostas a "Questão 6" dos alunos da Escola Estadual de Ensino FundamentalArroio Grande RS, Brasil (S: Sim; N: Não; NR: Não responderam).

No questionário inicial foi possível observar que $86 \%$ dos alunos desconheciam uma microalga (Figura 6). Após as atividades, esse conceito já se tornou ainda mais claro, onde $74,42 \%$ dos respondentes responderam sobre o conhecimento.Outro motivo é o fato dos seres abordados no tema, não serem visíveis a olho nu - "o que não é visualizado não é lembrado" - o que necessita a utilização de instrumentos especializados tais como microscópios.

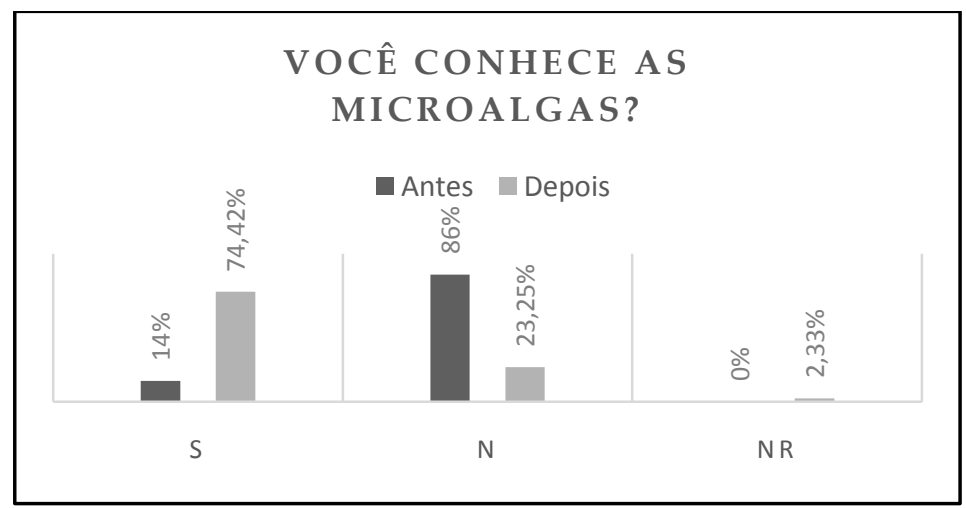

Figura 6. Respostas a "Questão 7" dos alunos da Escola Estadual de Ensino FundamentalArroio Grande RS, Brasil (S: Sim; N: Não; NR: Não responderam).

Constatou-se, desde o princípio, que tais conceitos seriam desconhecidos, primeiramente por não serem trabalhados em sala de aula ou não vistos com grande ênfase e frequência no cotidiano. Este fato, muitas vezes, deve-se ao desconhecimento ou pouco domínio do conteúdo do próprio educador e, ainda, por não ter a oportunidade de trabalhar alguns temas, tais como a educação ambiental de ambientes aquáticos, no período letivo onde há outros temas a serem abordados que muitas vezes são considerados mais importantes. Essas dificuldades foram observadas também por Costa e Braga 
(2015) ao desenvolver projetos de educação ambiental em escolas públicas e privadas de ensino fundamental do município de Ituiutaba-MG.

Por meio dos resultados obtidos nos questionários pode-se perceber que o conhecimento de conceitos após as atividades realizadas levou a uma maior percepção dos ambientes aquáticos próximos à escola, assim como 0 entendimento da presença das microalgas nesses ambientes. Atingindo o principal objetivo do presente trabalho, o de levar a informação e torna-la de fácil compreensão e atrativa por meio de uma atividade prática.

Nos questionários (antes e depois) foi possível constatar que todos tinham conhecimento de um ambiente aquático próximo da escola (Figura 7).

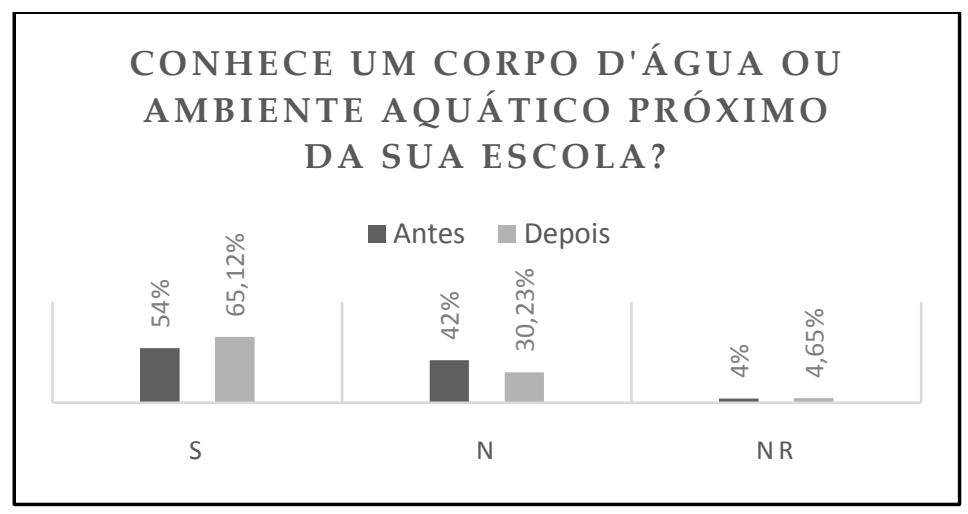

Figura 7. Respostas a "Questão 3" dos alunos da Escola Estadual de Ensino FundamentalArroio Grande RS, Brasil (S: Sim; N: Não; NR: Não responderam).

No questionário inicial $82 \%$ dos alunos desconheciam a existência de uma microalga nos ambientes aquáticos próximos a escola (Figura 8). Após as atividades, 53,48\% dos respondentes sabiam da existência.

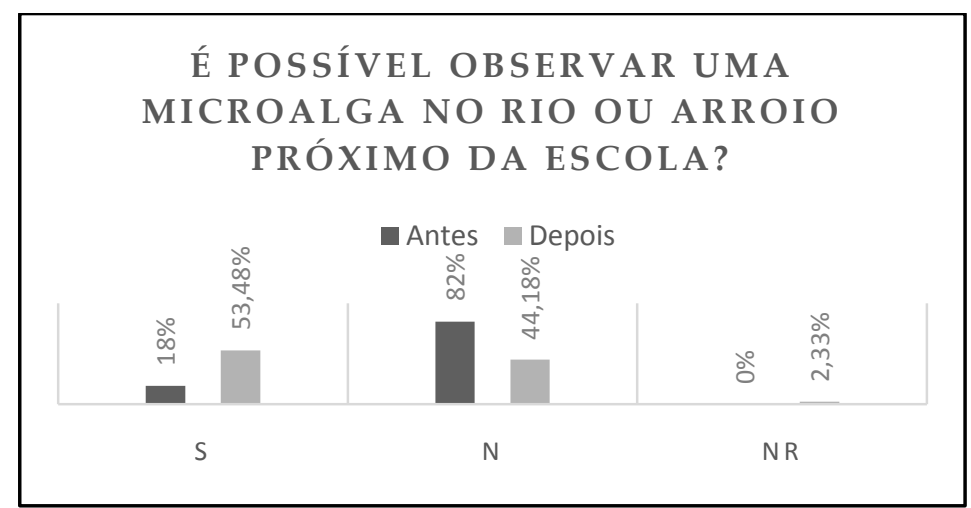

Figura 8. Respostas a "Questão 8" dos alunos da Escola Estadual de Ensino FundamentalArroio Grande RS, Brasil (S: Sim; N: Não; NR: Não responderam). 
Quando questionados a respeito dos motivos que tornam os rios importantes pode-se perceber que antes e depois da oficina as respostas foram semelhantes. As respostas mais presentes foram: consumo, hábitat de seres vivos, irrigação de lavouras, lazer entre outros. A resposta descrevendo os rios como de grande importância para a irrigação era esperada devido à realidade vivida na região, por se tratar de um local onde a orizicultura irrigada é bem presente (Figura 9).

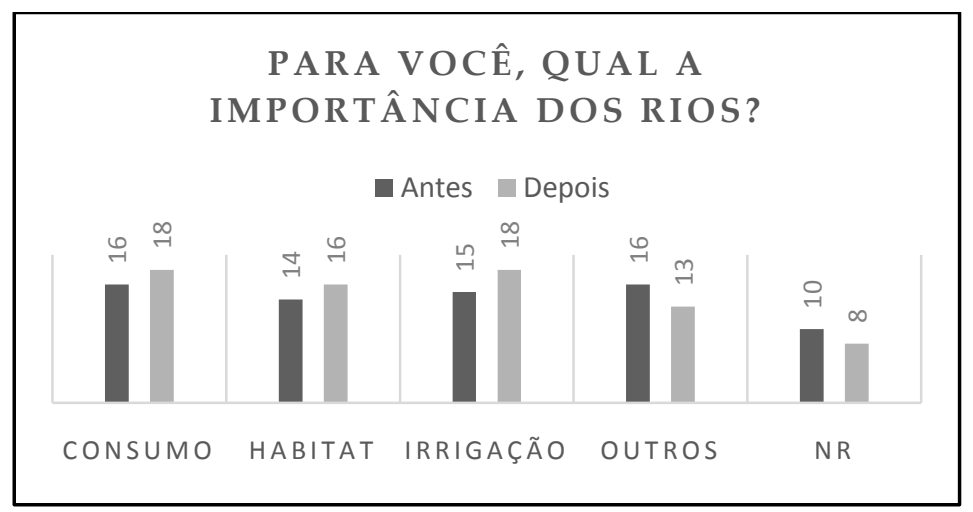

Figura 9. Respostas a "Questão 4" dos alunos da Escola Estadual de Ensino FundamentalArroio Grande RS, Brasil (NR: Não responderam).

A grande maioria dos discentes citou os peixes como os únicos seres vivos existentes nos rios. Embora esta resposta tenha permanecido, após a atividade, pode-se observar que aumentou consideravelmente os que passaram a levar em conta a existência das algas e microalgas nos ambientes aquáticos (Figura 10).

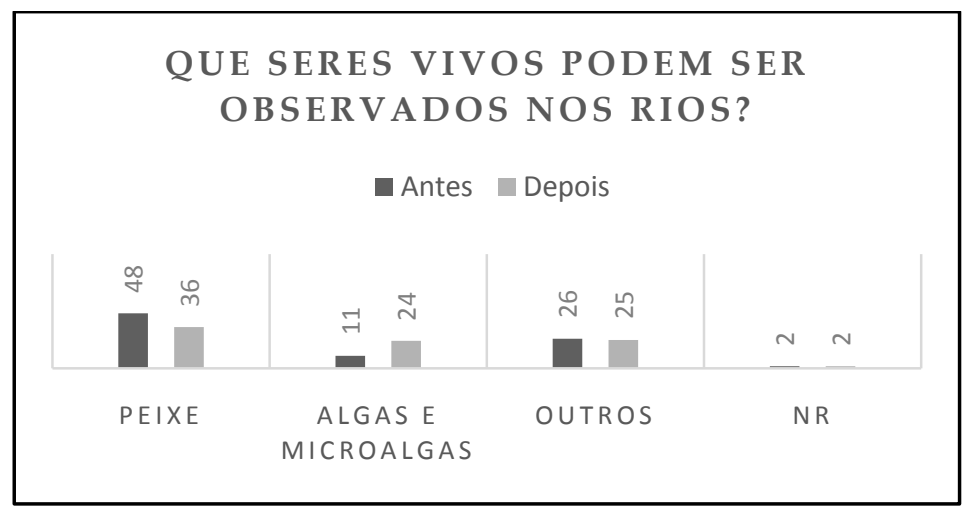

Figura 10. Respostas a "Questão 5" dos alunos da Escola Estadual de Ensino FundamentalArroio Grande RS, Brasil (NR: Não responderam).

Os organismos citados como presentes ambientes aquáticos também estavam presentes quando solicitados para que desenhassem 0 que 
observavam em um ambiente aquático. Nos desenhos do questionário anterior as atividades a presença de peixes era intensa quase unanime (Figura 11). Poucos retrataram a presença de algas e microalgas nos ambientes aquáticos no questionário que precedeu as atividades, aqueles que apresentavam acredita-se que talvez as próprias questões anteriores os induziram ao desenho. Posterior a palestra e oficina os desenhos assim como na resposta da questão 14 a existência de algas e microalgas nos ambientes aquáticos já estava mais claro (Figura 12).Nos desenhos pode-se constatar que os alunos observam o descaso com os ambientes aquáticos, onde muitos retrataram a presença de lixo nesses ambientes.

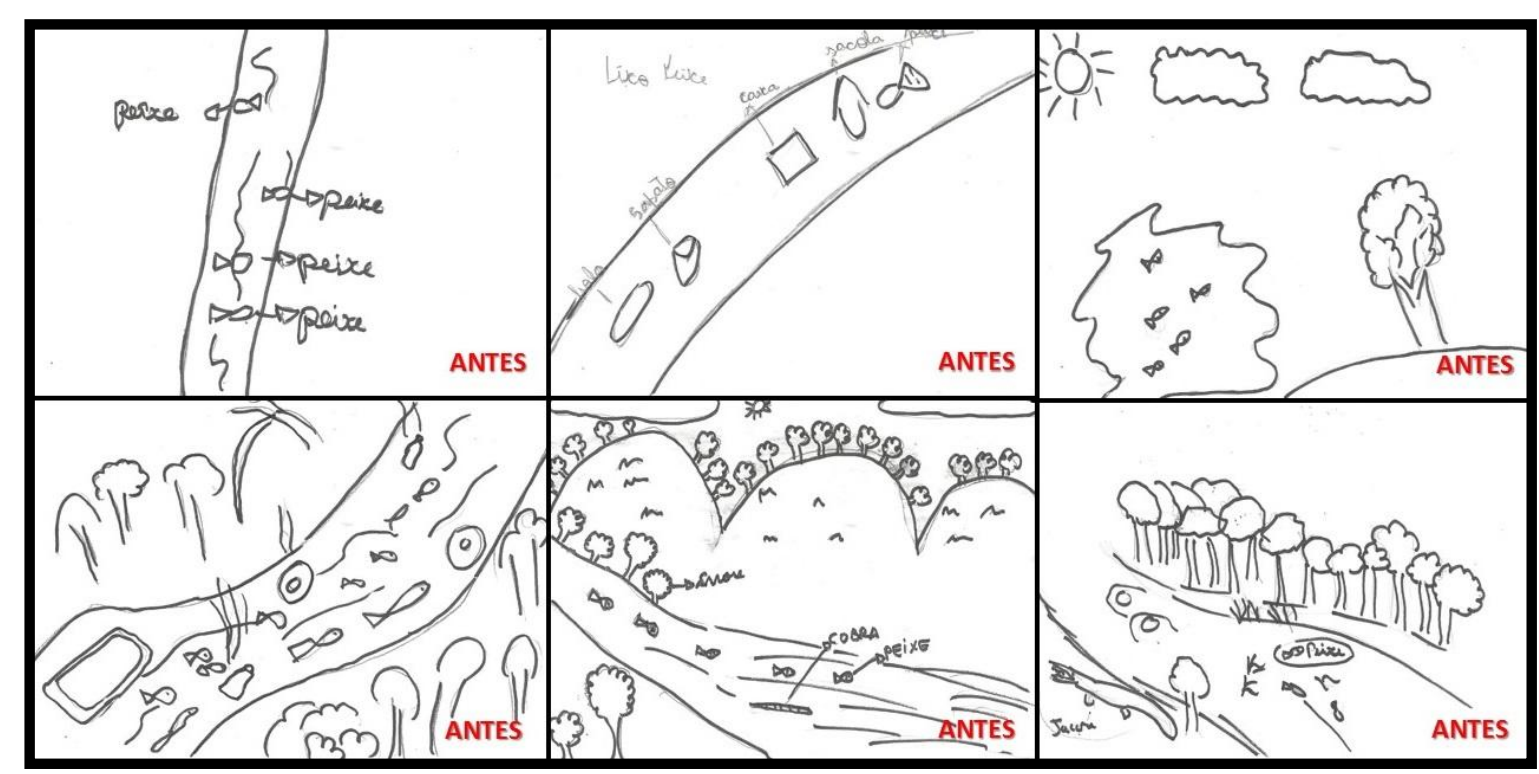

Figura 11. Respostas do pré-questionário da "Questão 10" dos alunos da Escola Estadual de Ensino FundamentalArroio Grande RS, Brasil. 


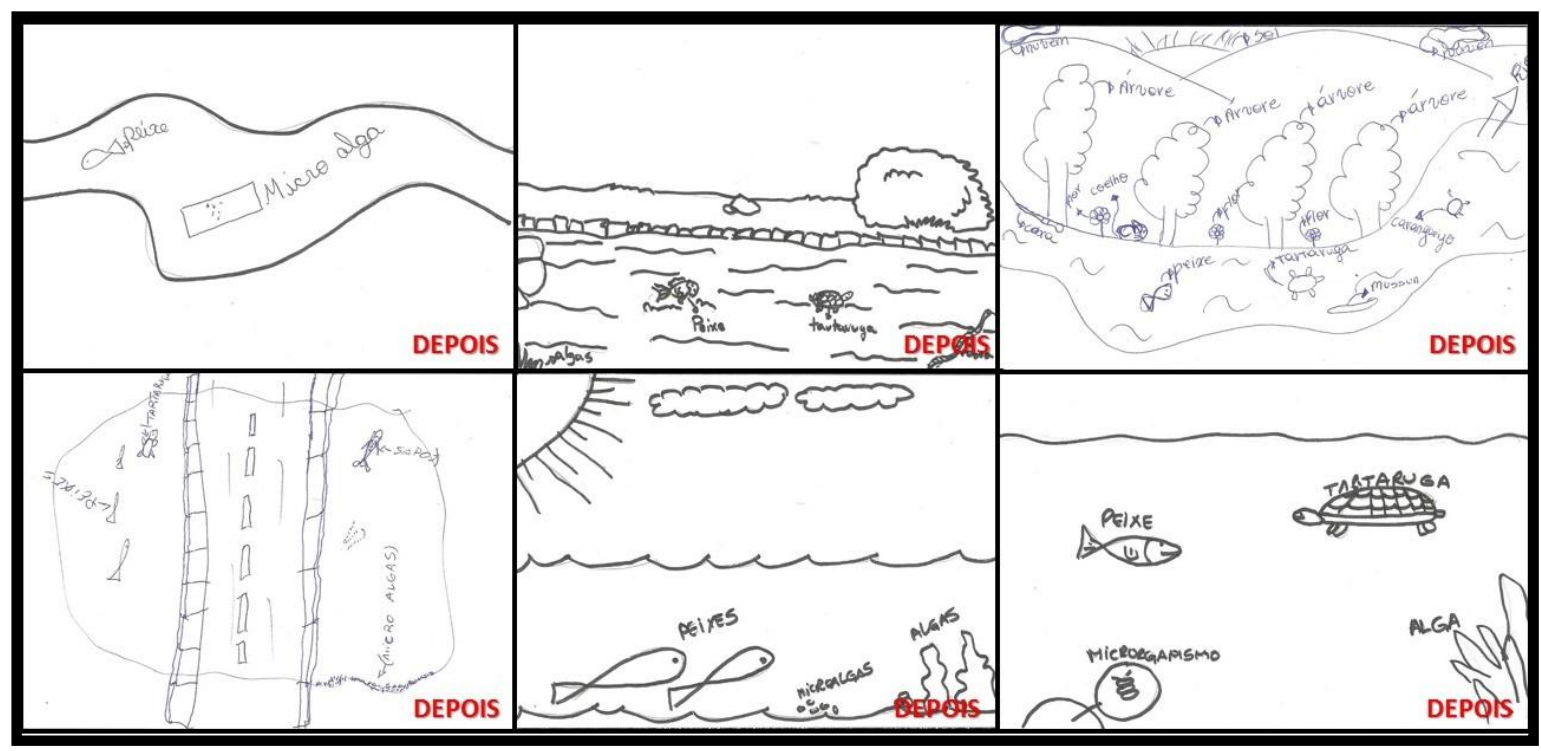

Figura 12. Respostas do pós-questionário da "Questão 10" dos alunos da Escola Estadual de Ensino FundamentalArroio Grande RS, Brasil.

Quando questionados a respeito da função que as algas e microalgas desempenhavam nos ambientes aquáticos (Figura 13), no momento anterior das atividades, grande parte desconhecia uma função, provavelmente porque desconheciam sua existência no ambiente aquático. Fato este que se modificou depois das atividades, onde destaques referentes ao seu papel na cadeia alimentar foram citados por grande maioria.

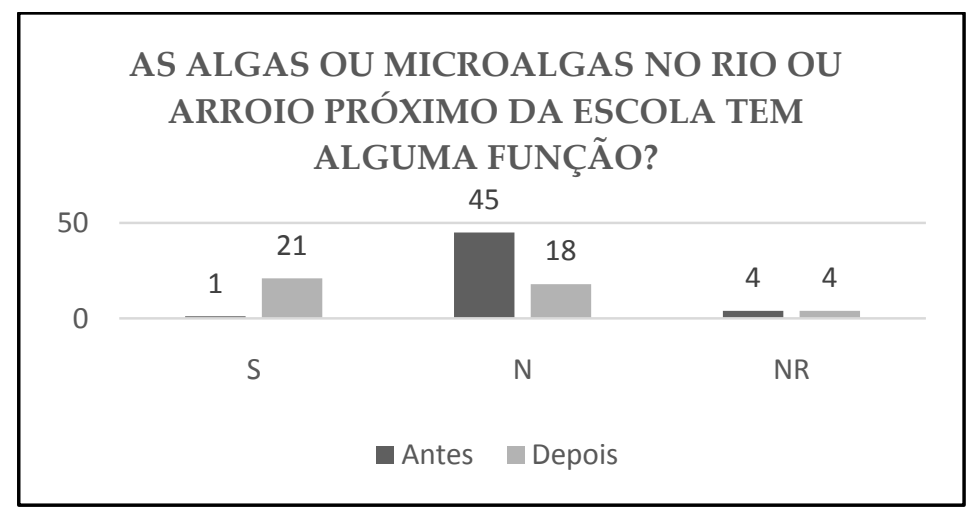

Figura 13. Respostas a "Questão 9" dos alunos da Escola Estadual de Ensino FundamentalArroio Grande RS, Brasil (S: Sim; N: Não; NR: Não responderam).

O pressuposto aqui é que, se o aluno aprender sobre a dinâmica dos ecossistemas, ele estará mais apto a decidir sobre os problemas ambientais e sociais de sua realidade quando for solicitado. Machado (1982) também afirma que só cuidamos, respeitamos e preservamos aquilo que conhecemos e que a ignorância traz uma visão distorcida da realidade. 
As atividades permitiram uma melhor compreensão dos ambientes aquáticos e organismos que ali habitam entre eles as microalgas foco do presente trabalho. Para Vasconcellos (1997), a presença, em todas as práticas educativas, da reflexão sobre as relações dos seres entre si, do ser humano com ele mesmo e do ser humano com seus semelhantes é condição imprescindível para que a Educação Ambiental ocorra. Dias (2000), acredita que Educação Ambiental seja um processo onde as pessoas apreendam como funciona o ambiente, como dependemos dele, como o afetamos e como promovemos a sua sustentabilidade.

Destacamos que com apenas um contato já houve uma enorme resposta positiva, para um trabalho ambiental completo e que proporcione maior abrangência seria interessante um trabalho a longo prazo com encontros e atividades periódicas. A maior abrangência, ou seja, os próprios alunos atuariam como locutores da mensagem preservacionista a família, amigos, vizinhos e demais pessoas de seu contato.

\section{CONCLUSÃO}

A partir do trabalho realizado pode-se confirmar o quanto a temática abordada era desconhecida da comunidade escolar e o quanto as atividades que tornem o aluno como agente ativo da busca do conhecimento facilitam a compreensão e a assimilação de conceitos. Nesse sentido, este trabalho cumpriu com o propósito de contribuir com conceitos e práticas sobre o tema "microalgas", orientando e sensibilizando discentes para a preservação dos corpos d'água. Os conceitos trabalhados foram satisfatoriamente compreendidos pelos alunosdo ponto de vista dos envolvidos na pesquisa e docentes da escola, a importância da preservação dos ambientes aquáticos assim como a função e importância das microalgas também.

\section{REFERÊNCIAS}

CARVALHO, I.C.M. Em direção ao mundo da vida: interdisciplinaridade e educação ambiental. Cadernos de Educação Ambiental Brasilia: IPÊInstituto de Pesquisas Ecológicas. 102pp. 1998. 
COSTA, V. F. BRAGA, H.F. Análise da implantação e desenvolvimento de projetos de educação ambiental em escolas públicas e privadas de ensino fundamental do município de Ituiutaba-MG.Revista Virtual Educação Ambiental em Ação. 2015. Disponível em: www.revistaea.org/artigo.php? Idartigo=2076. Acesso em: 20/07/2015.

EFFTING, T.R. Educação Ambiental nas Escolas Públicas: Realidade e Desafios. Marechal Cândido Rondon (Monography). Paraná: Pós Graduação em "Latu Sensu" Planejamento Para o Desenvolvimento Sustentável - Centro de Ciências Agrárias, Universidade Estadual do Oeste do Paraná - Campus de Marechal Cândido Rondon, 2007.

EVANGELISTA, L. M; SOARES, M. H. F. B. Atividades lúdicas no desenvolvimento da educação ambiental. In: Simpósio de Educação Ambiental e Transdisciplinaridade, UFG. Goiânia. 2011.

FUMAGALLI, L. El desafío de enseñarcienciasnaturales. Una propuestadidáctica para laescuela media. In: Weissmann, H.Didática das Ciências Naturais. Buenos Aires, p. 13-29. 1993.

LUNETTA, V.N. Atividades práticas no ensino da ciência. Revista Portuguesa de Educação.v(2): p.81-90. 1991.

LEITE, A. C. S.; SILVA, P. A. B.; VAZ, A. C. R. A importância das aulas práticas para alunos jovens e adultos: uma abordagem investigativa sobre a percepção dos alunos do PROEF. Disponível em:www.portal.fae.ufmg.br/seer/index.php/ensaio/article/viewFile/98/147. Acessado em:10/07/2015.

MACHADO, A.B.M. Conservação da natureza e educação. In: Congresso Nacional sobre Essências Nativas, Campos do Jordão. p.108-109, 1982.

MARQUES, J.G.W. Etnoecologia, educação ambiental e superação da pobreza em áreas de manguezais. Anais do 1ำ Encontro Nacional de Educação Ambiental em Áreas de Manguezais, Maragogipe, Brasil, p.29-35, 1993.

PEREZ, H. Biodiesel de microalgas. Parte I. Instituto de Pesquisas Energéticas e nucleares-IPEN. São Paulo, p. 1-19, 2007.

PONTALTI, E. S. Projeto de Educação Ambiental: Parque Cinturão Verde de Cianorte. Disponível me: http://www.apromac.org.br. Acessoem: 20/07/2015.

UNESCO-UNEP International strategy for action in the field of environmental education and training for the 1990s. Paris: UNESCO e Nairobi. 1987.

VASCONCELLOS, H.S.R. A pesquisa-ação em projetos de educação Ambiental. In: PEDRINI, A.G. (org). Educação Ambiental: reflexões e práticas contemporâneas. Petrópolis, Vozes, 1997. 